\title{
CORONARY ARTERY BYPASS GRAFTING IN PATIENTS WITH AN EJECTION FRACTION OF TWENTY PERCENT OR LESS
}

Tej K. Kaul, MD

Arvind K. Agnihotri, MD*

Barry L. Fields, MD

Lee S. Riggins, MD

David A. Wyatt, MD

Christopher R. Jones, MD
Over a 7-year period, $5.8 \%(n=210)$ of patients who underwent coronary artery bypass grafting at our institution had severely impaired global left ventricular function with an ejection fraction of $20 \%$ or less. Mean age at operation was 66 years $( \pm 0.7$; standard error), and $76 \%$ of patients were male. Primary indications for operation were unstable angina (73 patients, $35 \%$ ), return of symptoms with previous bypass grafting (41 patients, $20 \%$ ), congestive heart failure with reversible ischemia (55 patients, 26\%), and recurrent ventricular arrhythmias (41 patients, 20\%). Overall, actuarial survival ( $n=210$ ) was $82 \%, 79 \%$, and $73 \%$ at 1,2 , and 5 years. Risk of death was highest early after the operation, and then declined rapidly to a constant level. Patients who did not receive retrograde coronary sinus cardioplegia ( $p=0.05)$, older patients $(p=0.004)$, and those with preoperative ventricular arrhythmias $(p=0.003)$ or renal failure $(p<$ 0.0001 ) had an increased risk of death early after operation. Patients with congestive symptoms and those requiring extensive or redo bypass grafting $(p=0.02)$ were found to be at an increased risk of death throughout the follow-up period. When the number of distal anastomoses performed increased, survival was found to decrease $(p<0.003)$, and to a greater extent in women than in men $(p=0.02)$. Of the four primary indications for operation, unstable angina yielded the highest risk-adjusted survival. Successful results after surgical revascularization in patients with severe impairment of ventricular function can be achieved by careful patient selection and management. (J Thorac Cardiovasc Surg 1996;111:1001-12)
$R_{t}^{\mathrm{e}}$ evascularization of ischemic myocardium in patients with severely impaired global left ventricular (LV) function remains a surgical challenge. Despite advances in surgical technique and myocardial protection, perioperative mortality and morbidity remain high ${ }^{1-3}$ and long-term survival is poor. ${ }^{4}$ Death often results from progression of preoperative symptoms of congestive heart failure $(\mathrm{CHF})^{4-7}$ or ventricular arrhythmias, ${ }^{3,8,9}$ even though revascularization may result in initial improvement. ${ }^{4-6,10-13}$

Because alternative surgical treatments (i.e.,

From the Division of Cardiac Surgery, Princeton Baptist Medical Center, Birmingham, Ala.

Received for publication June 1, 1994; accepted for publication July 20, 1995

Address for reprints: Tej K. Kaul, MD, 817 Princeton Avenue, SW, Suite 300, Birmingham, AL 35211.

*Resident, Division of Cardiothoracic Surgery, University of Alabama at Birmingham Medical Center, Birmingham, Ala.

Copyright (c) 1996 by Mosby-Year Book, Inc.

$0022-5223 / 96 \$ 5.00+0 \quad \mathbf{1 2 / 1 / 6 7 9 9 4}$ transplantation and cardiomyoplasty) are limited ${ }^{14}$ and the results of medical therapy are often unsatisfactory, ${ }^{1}$ coronary artery bypass grafting $(\mathrm{CABG})$ is often the only available treatment that will improve symptoms and longevity. $2,5,10,15$ To quantify survival after $\mathrm{CABG}$ in these patients in whom the risk is high, and to characterize those most likely to benefit, we conducted a retrospective study.

\section{Patients and methods}

Patient selection. Between January 1, 1987, and December 31, 1992, 3621 patients underwent CABG at our institution. This study is based on the 210 patients $(5.8 \%$ of total) with severe impairment of global LV function who met the following criteria: (1) an LV ejection fraction of $20 \%$ or less, as assessed by area/length measurement on biplane LV cineangiogram; (2) evidence of reversible ischemia in the distribution of one or more major coronary arteries on dipyridamole thallium scintigraphy; and (3) evidence of operable coronary artery disease (CAD) on coronary angiography. Patients with an LV aneurysm $(n=11)$, severe segmental dysfunction with scar on thallium scan $(n=3)$, and those with a grossly dilated cardiomyopathy (LV end-diastolic dimension $>70 \mathrm{~mm}$ by 
Table I. Preoperative clinical details

\begin{tabular}{|c|c|c|c|c|c|c|c|}
\hline & & $\begin{array}{l}\text { ients } \\
210)\end{array}$ & & & $\begin{array}{r}A C C \\
(n\end{array}$ & $\begin{array}{l}\text { CSC } \\
\text { 7) }\end{array}$ & \\
\hline & No. & $\%$ & No. & $\%$ & No. & $\%$ & $p<$ \\
\hline Age $($ mean $66 \pm 0.7 \mathrm{yr})>70 \mathrm{yr}$ & 85 & 40.51 & 29 & 20 & 46 & 28 & 0.2 \\
\hline Female & 51 & 24.3 & 21 & 20 & 30 & 28 & 0.2 \\
\hline Male & 159 & 75.7 & 81 & 78.6 & 78 & 72.9 & 0.9 \\
\hline Coronary risk factors & & & & & & & \\
\hline Hypertension & 119 & 56.6 & 55 & 53 & 64 & 60 & 0.3 \\
\hline Diabetes mellitus & 43 & 20.5 & 20 & 19.4 & 23 & 21.5 & 0.1 \\
\hline Smoking & 92 & 43.8 & 42 & 40.7 & 50 & 46.7 & \\
\hline Family history & 44 & 20.95 & 23 & 22 & 25 & 24 & 0.8 \\
\hline Hyperlipidemia & 91 & 43.3 & 50 & 49 & 41 & 38 & 0.1 \\
\hline Clinical presentation & & & & & & & \\
\hline Unstable angina & 43 & 19 & 18 & 17.5 & 23 & 22 & 0.5 \\
\hline Recent myocardial infarction & 30 & 14.3 & 16 & 15.5 & 17 & 23 & 0.97 \\
\hline Recurring angina after previous CABG & 41 & 19 & 16 & 15.5 & 6.25 & 23 & 0.2 \\
\hline Stable angina-class IV & 50 & 25 & 25 & 24.3 & 25 & 23.3 & 0.3 \\
\hline CHF with reversible ischemia & 55 & 262 & 28 & 27 & 27 & 25 & 0.7 \\
\hline Ventricular arrhythmias (VT/VF) & 41 & 19.52 & 21 & 20 & 20 & 18.7 & 0.8 \\
\hline Peripheral vascular disease & 15 & 7.1 & 10 & 9.8 & 5 & 4.7 & 0.2 \\
\hline Cerebrovascular disease & 13 & 6.2 & 7 & 6.9 & 6 & 5.6 & 0.7 \\
\hline Previous cerebrovascular accident & 10 & 4.7 & 5 & 4.8 & 4 & 3.7 & 0.1 \\
\hline Chronic obstructive pulmonary disease & 25 & 11.9 & 16 & 15.5 & 9 & 8.4 & 0.2 \\
\hline Chronic renal failure (dialysis) & 9 & 4.3 & 6 & 5.8 & 3 & 2.8 & 0.3 \\
\hline ECG, Holter monitor, and echocardiographic fi & & & & & & & \\
\hline Old myocardial infarction & 60 & 28.57 & 28 & 27 & 32 & 30 & 0.2 \\
\hline Dilated cardiomyopathy (LVEDD $<70 \mathrm{~mm}$ ) & 41 & 19 & 20 & 19.4 & 21 & 19.6 & 0.2 \\
\hline Cardiac catherization and LV function & & & & & & & \\
\hline Left main coronary stenosis & 28 & 13.3 & 12 & 11.6 & 15 & 14 & 0.8 \\
\hline Triple vessel disease & 210 & 100 & 103 & 100 & 107 & 100 & - \\
\hline IABP support & 44 & 21 & 25 & 24 & 19 & 17.7 & 0.2 \\
\hline
\end{tabular}

$C A B G$, Coronary artery bypass graft; $C H F$, congestive cardiac failure; $V T / V F$, ventricular tachycardia/ventricular fibrillation; $E C G$, electrocardiographic: $L V E D D$, left ventricular end-diastolic dimension; $L V$, left ventricular; $L A B P$, intraaortic balloon pump; $A C C$, antigrade cardioplegia; $R C S C$, retrograde cardioplegia.

Table II. Preoperative hemodynamic and echocardiographic findings in 210 patients

\begin{tabular}{lcccc}
\hline & $\begin{array}{c}\text { Subgroup I } \\
(n=73)\end{array}$ & $\begin{array}{c}\text { Subgroup II } \\
(n=41)\end{array}$ & $\begin{array}{c}\text { Subgroup III } \\
(n=55)\end{array}$ & $\begin{array}{c}\text { Subgroup IV } \\
(n=41)\end{array}$ \\
\hline LVEDD (cm) & $5.4 \pm 0.6$ & $5.2 \pm 0.7$ & $6 \pm 0.8^{*}$ & $5.6 \pm 0.7$ \\
Echo, all patients & $29 \pm 3$ & $28 \pm 3$ & $46 \pm 0.8 \pm$ & $31 \pm 2$ \\
Mean PASP (mm Hg) & $13 \pm 2$ & $14 \pm 2.4$ & $17 \pm 2.6$ & $14 \pm 1.6$ \\
Mean PCWP $(\mathrm{mm} \mathrm{Hg})$ & $19 \pm 2$ & $23 \pm 1.6$ & $17 \pm 2.8$ & $22 \pm 2$ \\
LVSWI (gm/m/m $\left./ \mathrm{m}^{2}\right)$ & $4.8 \pm 0.2$ & $4.2 \pm 0.4$ & $3.2 \pm 0.6$ & $3.8 \pm 0.4$ \\
RVSWI $\left(\mathrm{gm} / \mathrm{m}^{2}\right)$ & 1600 & 1500 & 1360 & 1700 \\
SVRI (dyne $\left.\cdot \mathrm{sec} \cdot \mathrm{cm}^{-5}\right)$ (median) & & & \\
\hline
\end{tabular}

$L V E D D$, Left ventricular End-Diastolic dimension; PASP, pulmonary artery systolic pressure; PCWP, pulmonary capillary wedge pressure; $L V S W I$, left ventricular stroke work index; RVSWI, right ventricular stroke work index; $S V R I$, systemic vascular resistance index.

*Subgroup III versus subgroup II, $p<0.03$.

$\uparrow$ Subgroup III versus other subgroup, $p<0.05$.

echocardiography) ( $n=3$ ) were excluded from this series. Preoperative patient characteristics are summarized in Table I.

Indications for revascularization. Patients were classified as having one of four primary indications for CABG: unstable or postinfarction angina (subgroup I, $n=73$ ), recurrent angina after previous myocardial revasculariza- tion (subgroup II, $n=41$ ), CHF with reversible ischemia (subgroup III, $n=55$ ), and ventricular arrhythmias resulting in sudden cardiac collapse $(n=15)$ or syncope $(n=26)$ (subgroup IV, $n=41$ ). Table II provides hemodynamic and echocardiographic characteristics of patients in each subgroup. Table III summarizes their preoperative medications and cardiac support. 
Volume 111, Number 5

Table III. Preoperative medication and circulatory support

\begin{tabular}{|c|c|c|c|c|}
\hline & $\begin{array}{l}\text { Subgroup I } \\
(n=73)\end{array}$ & $\begin{array}{c}\text { Subgroup II } \\
(n=41)\end{array}$ & $\begin{array}{c}\text { Subgroup III } \\
(n=55)\end{array}$ & $\begin{array}{c}\text { Subgroup IV } \\
(n=41)\end{array}$ \\
\hline Digoxin & 5 & 5 & 38 & 12 \\
\hline Diuretics & 10 & 16 & 55 & 14 \\
\hline ACE inhibitors & Nil & 4 & 26 & 6 \\
\hline Phophodiesterase inhibitors & Nil & Nil & 12 & 2 \\
\hline Class I antiarrhythmic drugs & 12 & 6 & 14 & 41 \\
\hline Dopamine infusion & 20 & 12 & 28 & 12 \\
\hline IABP support & 6 & 4 & 15 & 16 \\
\hline
\end{tabular}

$A C E$, Angiotensin-converting enzyme; $L A B P$, intraaortic balloon pump.

Table IV. Operative characteristics of patients receiving antegrade versus retrograde (coronary sinus) cardioplegia

\begin{tabular}{|c|c|c|c|c|c|c|c|}
\hline \multirow[b]{3}{*}{ Operative characteristics } & \multirow[b]{3}{*}{ No. } & \multirow{3}{*}{$\begin{array}{c}\text { Percent of } \\
210\end{array}$} & \multicolumn{5}{|c|}{ Cardioplegia delivery } \\
\hline & & & \multicolumn{2}{|c|}{ Antegrade } & \multicolumn{3}{|c|}{ Retrograde } \\
\hline & & & No. & $\%$ of 103 & No. & $\%$ of 107 & $P\left(\chi^{2}\right)$ \\
\hline Bypass $>150 \mathrm{~min}$ & 90 & 43 & 49 & $\overline{48}$ & 41 & 38 & 0.2 \\
\hline Crossclamp $>100 \mathrm{~min}$ & 101 & 48 & 55 & 53 & 46 & 43 & 0.1 \\
\hline ITA used & 41 & 19.5 & 25 & 24 & 16 & 15 & 0.1 \\
\hline Four or more distal grafts & 132 & 62.9 & 76 & 74 & $56 \%$ & 52 & 0.001 \\
\hline Mean bypass time $(\min )$ & & & & $123 \pm 2.6$ & & $116 \pm 1.8$ & \\
\hline Mean crossclamp time (min) & & & & $88 \pm 2.1$ & & $80 \pm 2.1$ & \\
\hline
\end{tabular}

ITA, Internal thoracic artery.

Management. Emergency CABG (within 6 hours of a cardiac catheterization) was performed in 44 patients (21\% of 210); six had unstable angina (subgroup I) and 38 had hemodynamic collapse (subgroup 4). Urgent CABG (between 6 and 48 hours) was performed in 100 patients $(48 \%) ; 67$ were in subgroup I, 15 in subgroup II, 15 in subgroup III, and 3 in subgroup IV. An intraaortic balloon pump was placed when, despite inotropic support, blood pressure was less than $90 \mathrm{~mm} \mathrm{Hg}$, cardiac index was less than $2.0 \mathrm{~L} / \mathrm{m}^{2}$, or $\mathrm{LV}$ end-diastolic pressure was greater than $20 \mathrm{~mm} \mathrm{Hg}$. All patients with known concomitant high-grade internal carotid stenosis $(>85 \%$ on cerebral angiography) underwent simultaneous carotid endarterectomy and myocardial revascularization. Management of peripheral vascular lesions was by staged revascularization. In patients with end-stage renal disease, maintenance dialysis was resumed after myocardial revascularization.

A thermodilution catheter was routinely placed before induction of anesthesia. Standard cardiopulmonary bypass, moderate hypothermia $\left(28^{\circ} \mathrm{C}\right)$, cold blood cardioplegia, and topical cooling were used in all patients. Before September 1988, cardioplegic solution was usually delivered via the antegrade route. Since October 1988, combined antegrade and retrograde cardioplegia (via the coronary sinus) has been attempted on all patients in whom the risk was high (including those who met criteria for this study). Patients were not randomized as to the route of delivery of the cardioplegic solution. Of the 210 patients in this study, $103(48 \%)$ received antegrade cardioplegia only, and in 107 (51\%), combined antegrade
Table V. Management of patients with documented or suspected ventricular arrhythmias after $C A B G$ : Electrophysiologic testing $(n=72)$

Inducible sustained VT/VF $(n=47)$

Pharmacologically resistant VT/VF $(n=17)$

1. AICD $(n=13)$

2. Endocardial ablation $(n=4)$ (failure of AICD)

$\mathrm{VT} / \mathrm{VF}$ terminated by drugs $(n=30)$

1. Amiodarone $(n=12)$

2. Mexiletene $(n=6)$

3. Procainamide $(n=4)$

4. Encaide $(n=3)$

5. Mixed $(n=5)$

Noninducible VT/VF $(n=25)+$ other survivors $(n=107)$

Class I antiarrhythmic drugs as indicated

$V T / V F$, Ventricular tachycardia/fibrillation; $A I C D$, automatic implantable cardioverter-defibrillator. Survivors with preoperative VT/VF, $n=30 / 41$ survivors with postoperative VT/VF, $n=14 / 23$. All deaths occurred in patients who also had preoperative VT/VF. Survivors after sudden cardiac death in patients discharged after $\mathrm{CABG}$, 7/9; syncope, $n=21$.

and retrograde cardioplegia was used. In three patients coronary sinus perfusion was attempted but was unsuccessful, and they received only antegrade cardioplegia (and are counted among the 103 "antegrade only" patients). Tables I and IV list the preoperative and operative characteristics of the patients in the two cardioplegic delivery groups.

Eighty-four patients (40\%) required intraaortic balloon pump support for low cardiac output (preoperatively in 


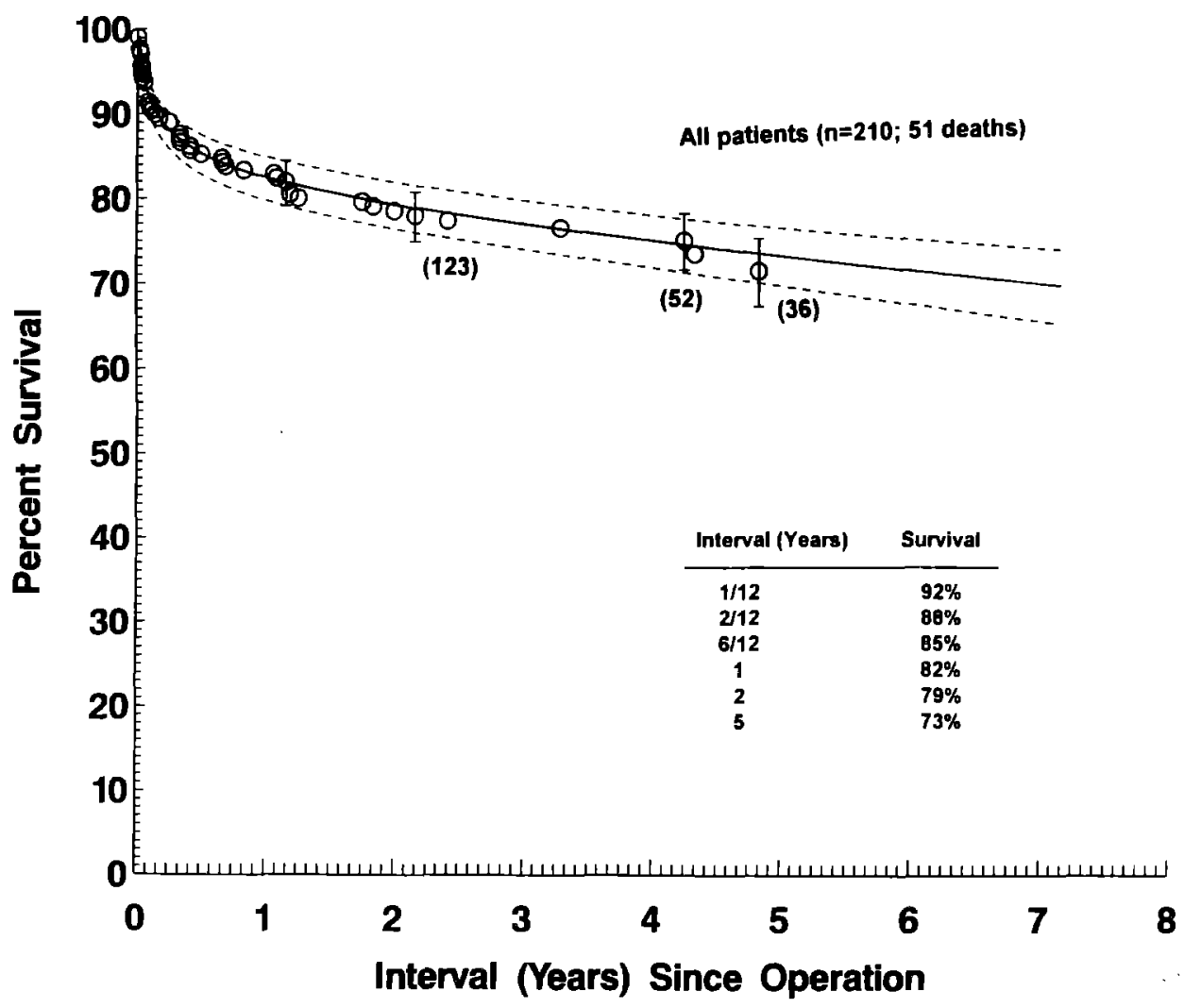

Fig. 1A. Time-related survival after $C A B G$ in patients with preoperative ejection fraction less than or equal to $20 \%$. Circles represent individual deaths, positioned along the horizontal axis at the interval between operation and the time of death and, actuarially (Kaplan-Meier method), along the vertical axis. The vertical bars represent $70 \%$ confidence limits. Numbers in parentheses represent the number of patients continuing to be followed up after that time. The solid line represents the parametrically estimated survival, and the dashed lines enclose the $70 \%$ confidence limits of that estimate. The table provides parametric estimates at specified intervals.

44, postoperatively in 40). Three patients required an LV assist device when placement of a balloon pump alone did not permit discontinuation of cardiopulmonary bypass. Only patients with recurrent angina underwent a second coronary angiography.

There were 76 patients with a history (known or suspected) of ventricular arrhythmias. These patients include survivors of preoperative ventricular tachycardia/fibrillation (VT/VF) $(n=30)$, those with documented postoperative VT/VF $(n=14)$, patients with syncopal or presyncopal episodes during follow-up $(n=25)$, and survivors of sudden cardiac collapse requiring cardiopulmonary resuscitation $(n=7)$. Because these patients were at high risk for recurrent VT/VF, they underwent postoperative testing: Holter monitor studies were performed in all patients and $72(95 \%)$ underwent programmed electrophysiologic testing. Management was based on the results of testing as depicted in Table V.

Follow-up. Perioperative information was obtained from hospital records. Complete cross-sectional follow-up (all 210 patients) was conducted between April 30 and June 30,1994, by questionnaires, telephone conversations, and review of outpatient records. Among survivors, the interval from operation to last contact averaged 43 months ( \pm 17 months, 1 standard deviation), with a range of 15 to 86 months.

Definitions: Unstable angina: Persistent anginal symptoms with ST-T changes in the electrocardiogram necessitating nitroglycerin and heparin administration.

Postinfarction angina: Persistent angina symptoms with ST-T changes in the same area where q waves appeared earlier, or evidence of extension of infarct on thallium scan. Angina and functional classification are as described by Goldman, Hashimoto, and Cook. ${ }^{16}$

Operable CAD: Stenosed vessels with internal diameter less than $1 \mathrm{~mm}$, or with a diameter greater than $1 \mathrm{~mm}$ in the absence of diffuse or distal disease. Some patients with operable CAD, especially in subgroups II and III, did have inoperable vessels in some distributions (i.e., small vessels with diffuse distal disease).

CHF: One or more episodes of fluid retention necessitating diuretic therapy within 3 months of operation.

Ischemic cardiomyopathy: Cardiac dilatation caused by ischemic myocardial degeneration. ${ }^{17}$ 


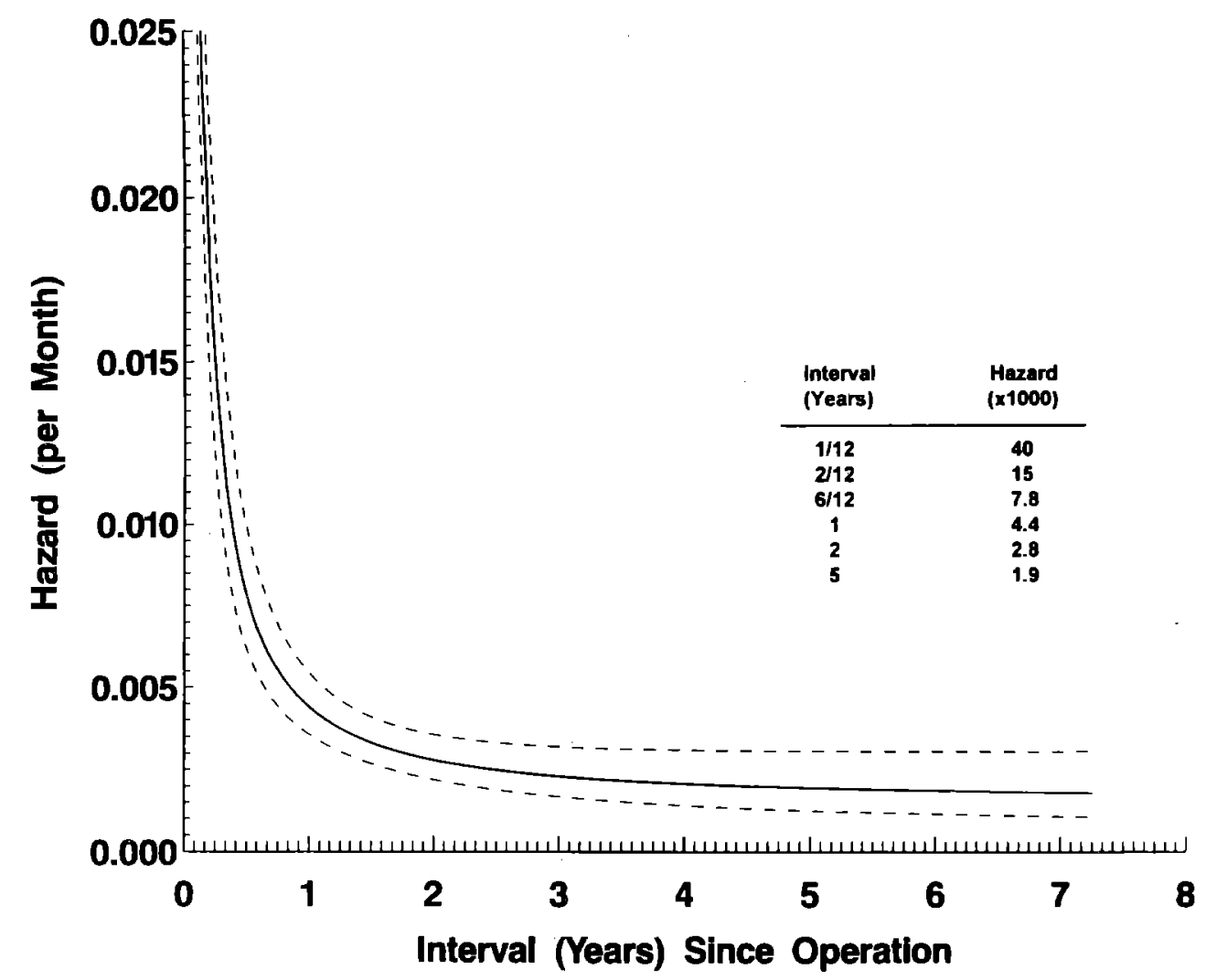

Fig. 1B. Hazard function for death after CABG. The hazard function has two phases, an early declining phase and a constant phase. The table provides hazard estimates at specified intervals.

Monomorphic VT: VT with uniform QRS morphology in leads $\mathrm{I}, \mathrm{aV}_{\mathrm{F}}$, and $\mathrm{V}_{1}$.

Polymorphic VT: VT with changes in axis (>45\%) or altitude $(>50 \%)$ or both.

Sustained VT: Monomorphic or polymorphic VT lasting for more than 30 seconds with a heart rate greater than 100 beats/min.

Standard electrophysiology protocol: A standard program of electrophysiologic stimulation used after antiarrhythmic medication was discontinued and cleared (at least 5 half-lives). During the protocol, patients may have experienced induced $V F$, defined as a disorganized rhythm with hemodynamic instability necessitating direct-current shock, or sustained induced $V T / V F$, defined as VT/VF lasting 30 seconds or more and necessitating termination of stimulation.

LV stroke work index is stroke work index (mean arterial pressure - pulmonary capillary wedge pressure) $\times 0.0136$ $\mathrm{gm} / \mathrm{mm}$ per square meter.

Right ventricular stroke work index is stroke work index (mean pulmonary artery pressure - right atrial pressure) $\times 0.0136 \mathrm{gm} / \mathrm{mm}$ per square meter.

Systemic vascular resistance index is (mean arterial pressure - right atrial pressure $) \times$ cardiac output $\times 80$ dynes $\cdot \mathrm{sec} \cdot \mathrm{cm}^{-5}$.

Statistical analysis. Values are expressed as mean \pm standard error of the mean or, when stated, \pm standard deviation. Univariate associations between concomitant variables and patient death were assessed by two-way contingency tables for discrete variables, by two-sample $t$ test for continuous variables, and by logistic analysis for ordinal variables. Stratified Kaplan-Meier depictions ${ }^{18}$ were used to explore time-related differences between subgroups of patients with various combinations of potential risk factors.

The time-related risk of death was modeled by means of a generic three-phase hazard method. ${ }^{19}$ Hazard functions were also generated independently for the group of patients who received cardioplegic solution solely by the antegrade method and for those in whom cardioplegic solution was delivered by a combined antegrade/retrograde route.

Determinants of postoperative death were identified by multivariate analysis, within each phase of hazard. Variables listed in Table I were considered in the analysis. Transformations of scale for continuous and ordinal variables were made to optimize their linear relationship in the logistic domain. During the process of developing a parsimonious equation, variables were entered into the model sequentially by means of a direct, nonautomated technique. A maximum $p$ value of 0.05 (likelihood ratio test) was accepted for retaining a variable in the model. 


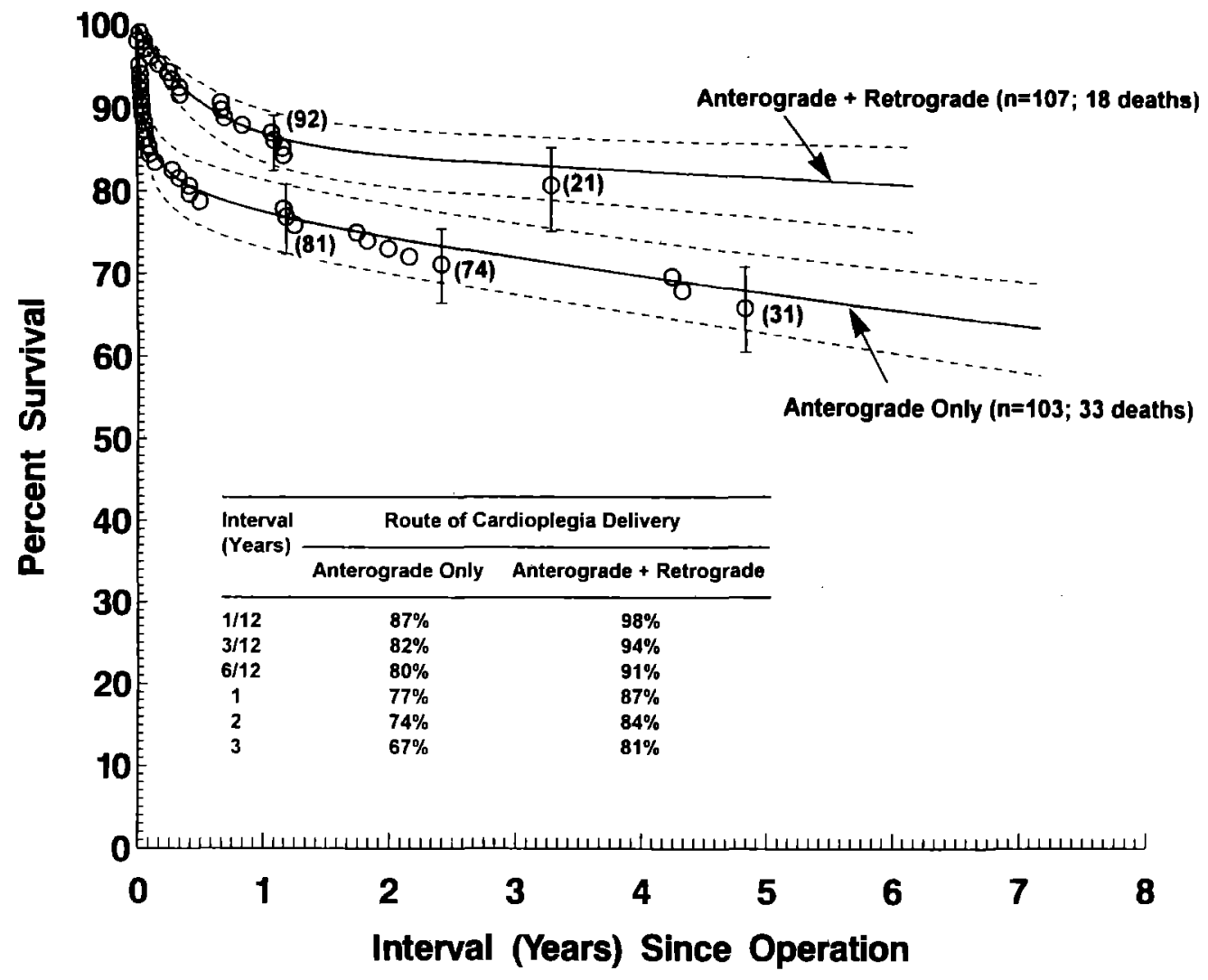

Fig. 2A. Time-related survival stratified by the route of cardioplegic delivery. The depiction is similar to that in Fig. 1A.

Table VI. Incremental risk factors for death after $C A B G$ in patients with an ejection fraction $<20 \%$ ( $n=210$; 51 deaths)

\begin{tabular}{|c|c|c|c|c|}
\hline \multirow[b]{3}{*}{ Risk factor } & \multicolumn{4}{|c|}{ Hazard Phase } \\
\hline & \multicolumn{2}{|c|}{ Early } & \multicolumn{2}{|c|}{ Constant } \\
\hline & Coefficient $+S E$ & $p<$ & Coefficient $\pm S E$ & $p<$ \\
\hline \multicolumn{5}{|l|}{ Demographic } \\
\hline Age (older) & $0.07 \pm 0.023$ & 0.004 & & \\
\hline \multicolumn{5}{|l|}{ Clinical history } \\
\hline Renal dysfunction & $2.0 \pm 0.48$ & 0.0001 & & \\
\hline Preoperative VT or VF & $1.1 \pm 0.38$ & 0.003 & & \\
\hline Preoperative CHF & & & $1.8 \pm 0.82$ & 0.02 \\
\hline Previous CABG & & & $2.6 \pm 0.88$ & 0.004 \\
\hline \multicolumn{5}{|l|}{ Operative } \\
\hline $\begin{array}{l}\text { Nonuse of CS cardioplegia } \\
\text { No. of distal anastomoses } \geq 4\end{array}$ & $0.7 \pm 0.39$ & 0.05 & & \\
\hline Male (interaction) & & & $0.7 \pm 0.38$ & 0.003 \\
\hline Female (interaction) & & & $1.2 \pm 0.34$ & 0.0002 \\
\hline Intercepts & $-6.7 \pm 1.7$ & $<0.0001$ & $-11.4 \pm 2.1$ & $<0.0001$ \\
\hline
\end{tabular}

Log likelihood $=-234.51$.

Shaping parameters: $\rho=1.867 ; \delta=0 ; v=2.595 ; \mathrm{m}=0$.

$V T$ or VF, Ventricular tachycardia or fibrillation; $C H F$, congestive heart failure; $C S$, coronary sinus. 


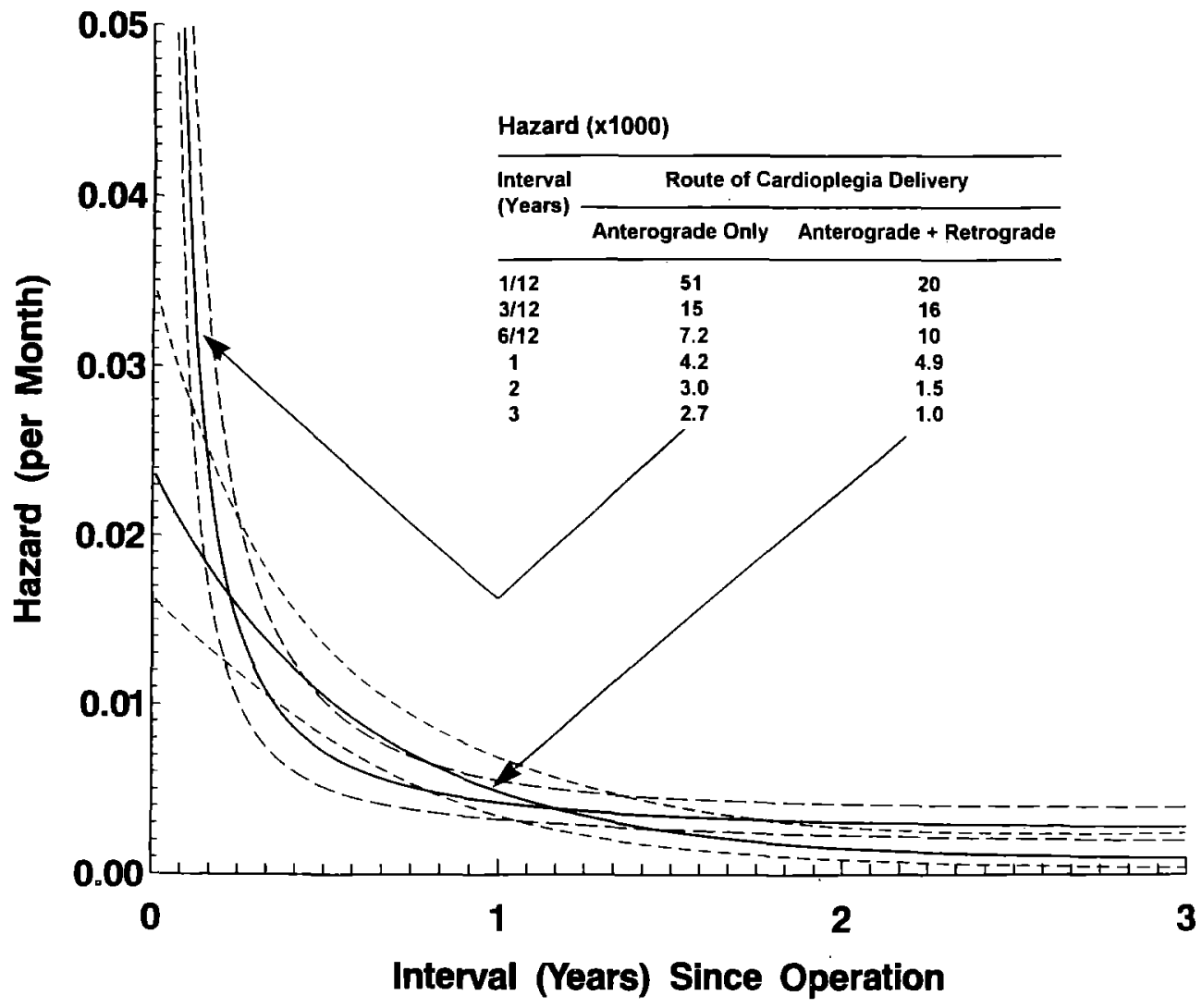

Fig. 2B. Hazard functions determined independently for the two routes of cardioplegic delivery. Note that the horizontal axis has been expanded to allow better visualization of early risk. The depiction is otherwise similar to that in Fig. 1B.

To illustrate the effect of individual risk factors, we generated nomograms (specific solutions of the multivariable equation) by solving the equation for different values of the variable of interest while simultaneously holding the value of all other variables constant. In graphic depictions, values are shown along with $70 \%$ confidence limits ( \pm 1 standard deviation).

\section{Results}

Survival. There were 51 deaths $(24 \%$ of 210$)$. Twenty-one deaths occurred before hospital discharge (maximum postoperative stay was 45 days). Actuarial survival is depicted in Fig. 1A. The hazard function for death was biphasic, with an early declining and a later constant phase (Fig. 1B). Multivariate analysis identified determinates of postoperative survival, listed in Table VI.

Survival was superior in patients who received combined antegrade and retrograde cardioplegia, versus antegrade only, because of a reduction in the risk of death early after operation $(p=0.05$,
Table VI, Figs. 2A and 2B). Actuarial survival in patients with preoperative VT/VF, identified as an early risk factor, is depicted in Fig. 3. Older age also increased early risk $(p=0.004)$, but its effect was weak and most pronounced when there were other risk factors.

When the number of distal anastomoses was large, risk of death was higher in both men ( $p=$ $0.003)$ and women $(p=0.0002)$. This negative association with survival was more pronounced in women than in men ( $p=0.02$, Fig. 4), and overall actuarial survival was higher in men $(p=0.04$, Fig. 4). Patients with preoperative CHF had decreased survival (Fig. 5), and in women with $\mathrm{CHF}$, predicted 5 -year survival was only $20 \%$ (Fig. 5).

Actuarial survival of patients, stratified by primary indication for operation (subgroups I to IV; see Methods) was not believably different (5-year survival was $73 \%$ for subgroup I, $52 \%$ for subgroup II, $55 \%$ for subgroup III, and 52\% for subgroup IV; 


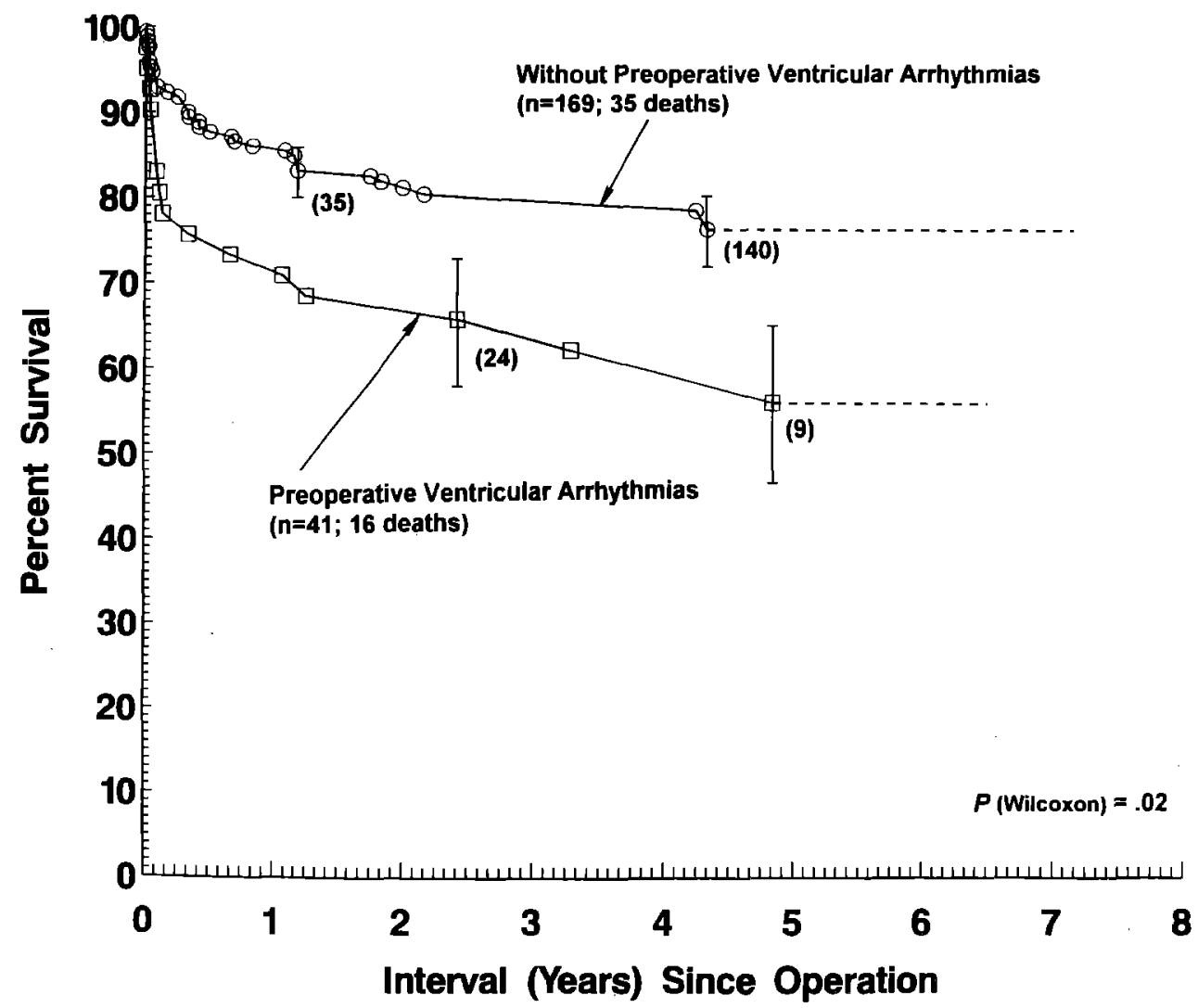

Fig. 3. Time-related survival stratified by presence of preoperative ventricular arrhythmias (tachycardia or fibrillation). Symbols represent individual events: squares for patients who had preoperative arrhythmias and circles for patients who did not, positioned along the horizontal axis at the interval from operation to death and actuarially along the vertical axis. The vertical bars represent $70 \%$ confidence limits. Numbers in parentheses represent the number of patients continuing to be followed up after that time.

$p=0.4)$. However, by risk-adjusted analysis, patients who had unstable angina (subgroup I) had the highest survival, because patients in all other subgroups must, by definition, have one or more identified risk factors.

Of the 80 patients $(40 \%)$ who required preoperative or postoperative balloon pump support, 26 patients $(33 \%)$ died.

Ventricular arrhythmias. Patients treated by the electrophysiologic protocol (those identified at increased risk for arrhythmic complications) had a lower risk of sudden cardiac death (none vs 9) and greater actuarial freedom from postoperative VT/VF ( $83 \%$ vs $74 \%$ at 5 years), but these differences could be due to chance alone ( $p=$ not significant, Fig. 6).

Functional status. Among those alive at the time of cross-sectional follow-up, New York Heart Association class was found to be lower than it was before the operation (preoperative $3.48 \pm 0.04$ vs last contact $1.55 \pm 0.05 ; p=0.005$ ).

Fifty patients had recurrent or progressive angina that required evaluation. The angina was severe in 14 patients and mild or equivocal in 36. Angiography disclosed a correctable lesion in six patients (all with severe angina), and they eventually underwent successful angioplasty. Progressive ischemic cardiomyopathy developed in 16 patients, and four were listed for cardiac transplantation.

\section{Discussion}

Patient survival. Multiple studies have shown that patients with severe global LV dysfunction caused by $\mathrm{CAD}$ respond better with myocardial revascularization than with medical therapy alone. ${ }^{2,5,10,15}$ Surgical intervention is known to be most beneficial in patients who are at highest risk with conventional medical therapy. ${ }^{20}$ When patients 


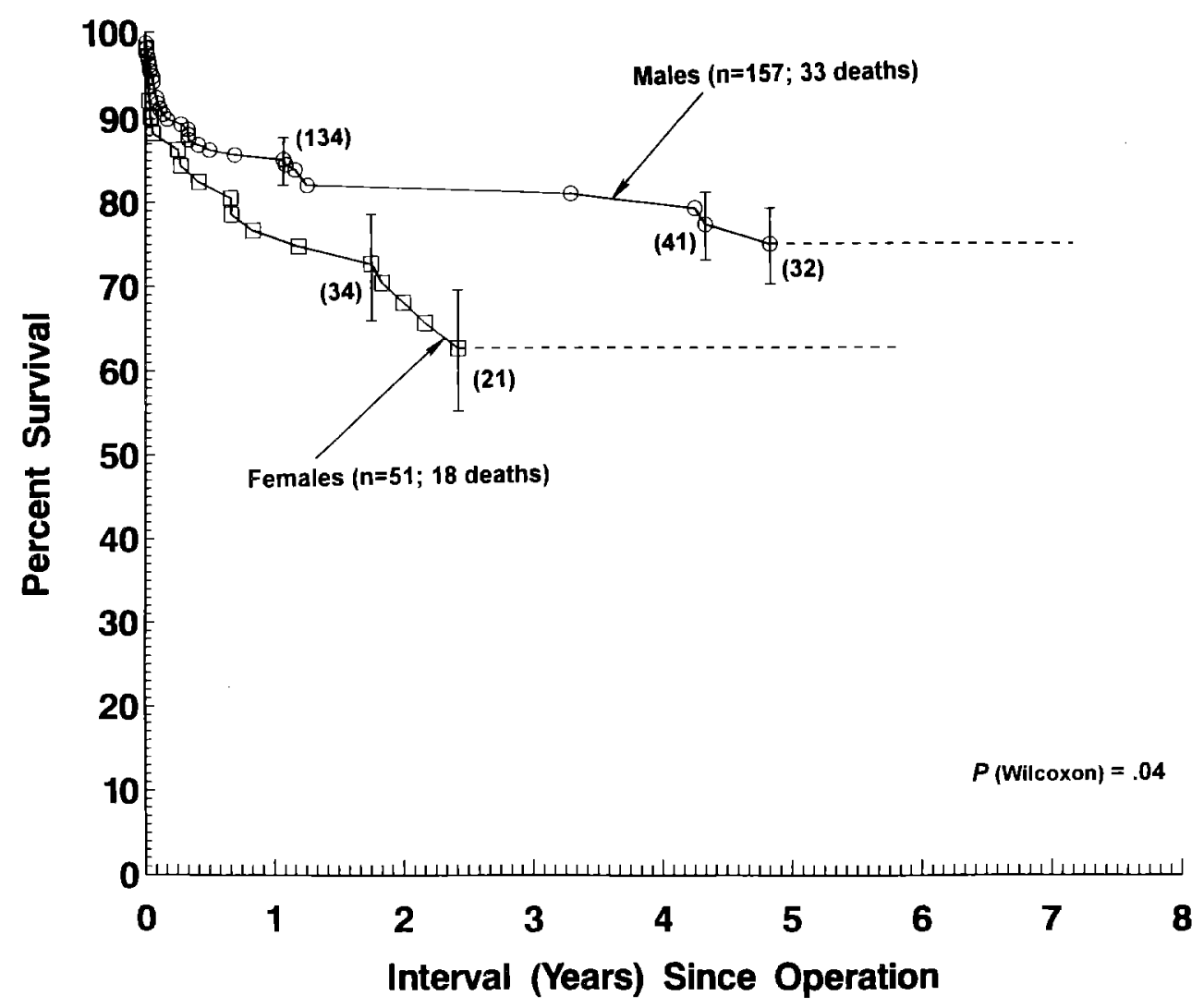

Fig. 4. Time-related survival stratified by gender. The depiction is similar to that in Fig. 3 .

have ischemic or acutely injured myocardium, ${ }^{1,16}$ revascularization has been shown to prolong life expectancy, ${ }^{21}$ improve functional status, ${ }^{14,20}$ and diminish the prevalence of sudden cardiac deaths caused by arrhythmias. ${ }^{8,10}$ Because cardiac transplantation is limited by donor supply (and many of these patients would make poor candidates owing to advanced age and coexistent diseases), surgical revascularization may offer the only chance for significant improvement.

In the past, perioperative mortality after $\mathrm{CABG}$ in patients with poor $\mathrm{LV}$ function has been reported to be between $10 \%$ and $37 \%,{ }^{1-3}$ but more recent reports indicate a much lower mortality $(2.3 \%$ to $5 \%$ ), attributed to advances in myocardial management and surgical technique., ${ }^{92-24}$ Studies have now documented 5-year survival after CABG approaching $80 \%$. 9

Myocardial protection. Studies indicate that blood cardioplegia is superior to asanguineous cardioplegia $^{1}$ and that retrograde coronary sinus cardioplegia may provide a more uniform myocardial protection in patients with severe multivessel disease. ${ }^{25,26}$ Our findings (although resulting from a nonrandomized experience) are in support of these concepts. We found the risk of death among patients who received retrograde cardioplegia to be lower, but only in the early postoperative period (Fig. 2B). These findings are consistent with the theory that retrograde delivery improves cardioplegic protection, which may result in a critical improvement in cardiac performance during the early postoperative period.

Unfavorable patient characteristics. Increased perioperative mortality after CABG in patients with depressed LV function has previously been associated with advanced age, female gender severity of CAD (left main disease, diffuse and multivessel CAD), inadequate myocardial protection, ventricular irritability, and development or persistence of CHF after the operation. ${ }^{1,6}$ Our findings are consistent with these observations.

In this series, $40 \%$ of patients were 70 years old or older and their perioperative mortality was $14 \%$. 


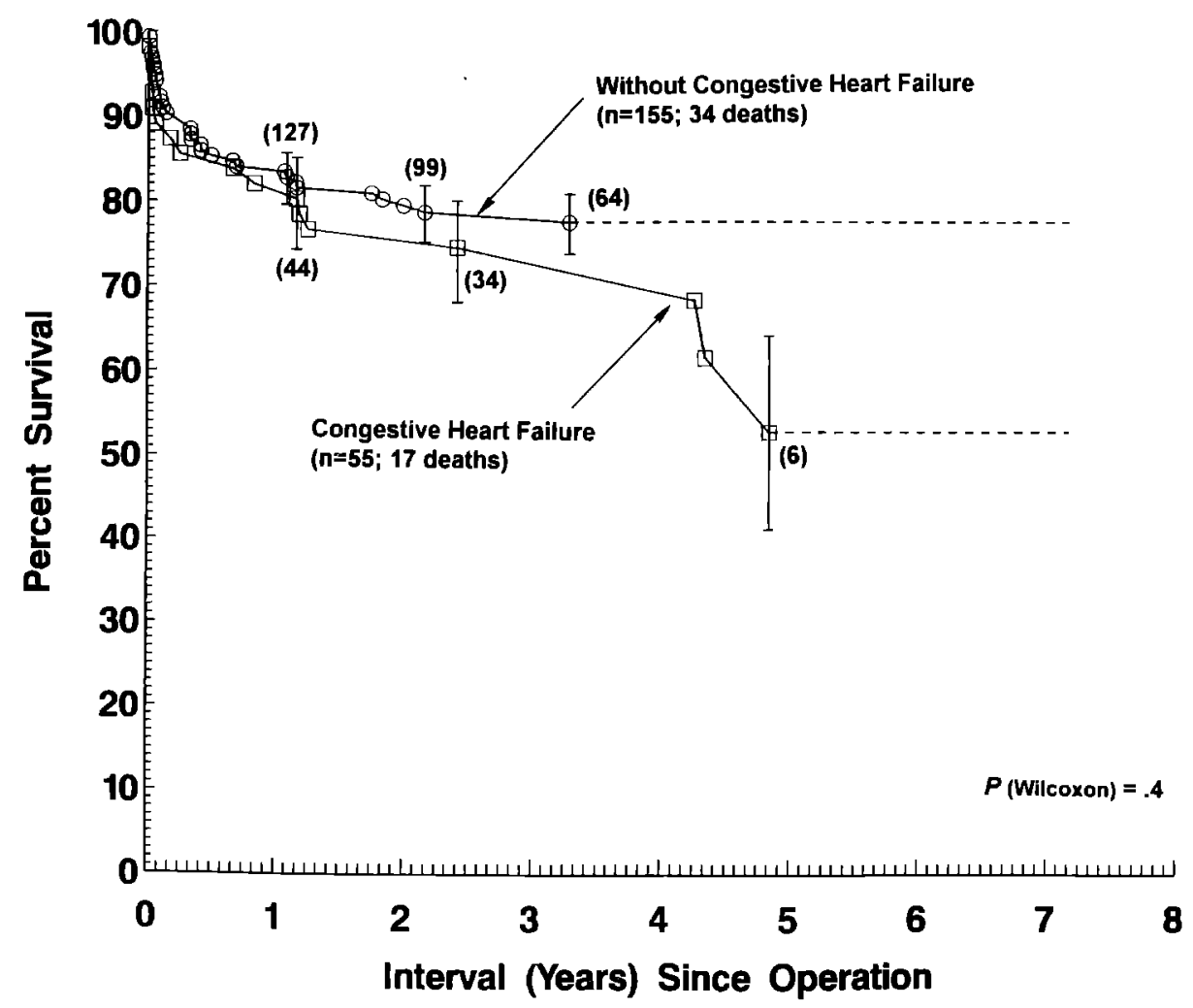

Fig. 5. Time-related survival stratified by presence of preoperative CHF. Depiction is similar to that in Fig. 3.

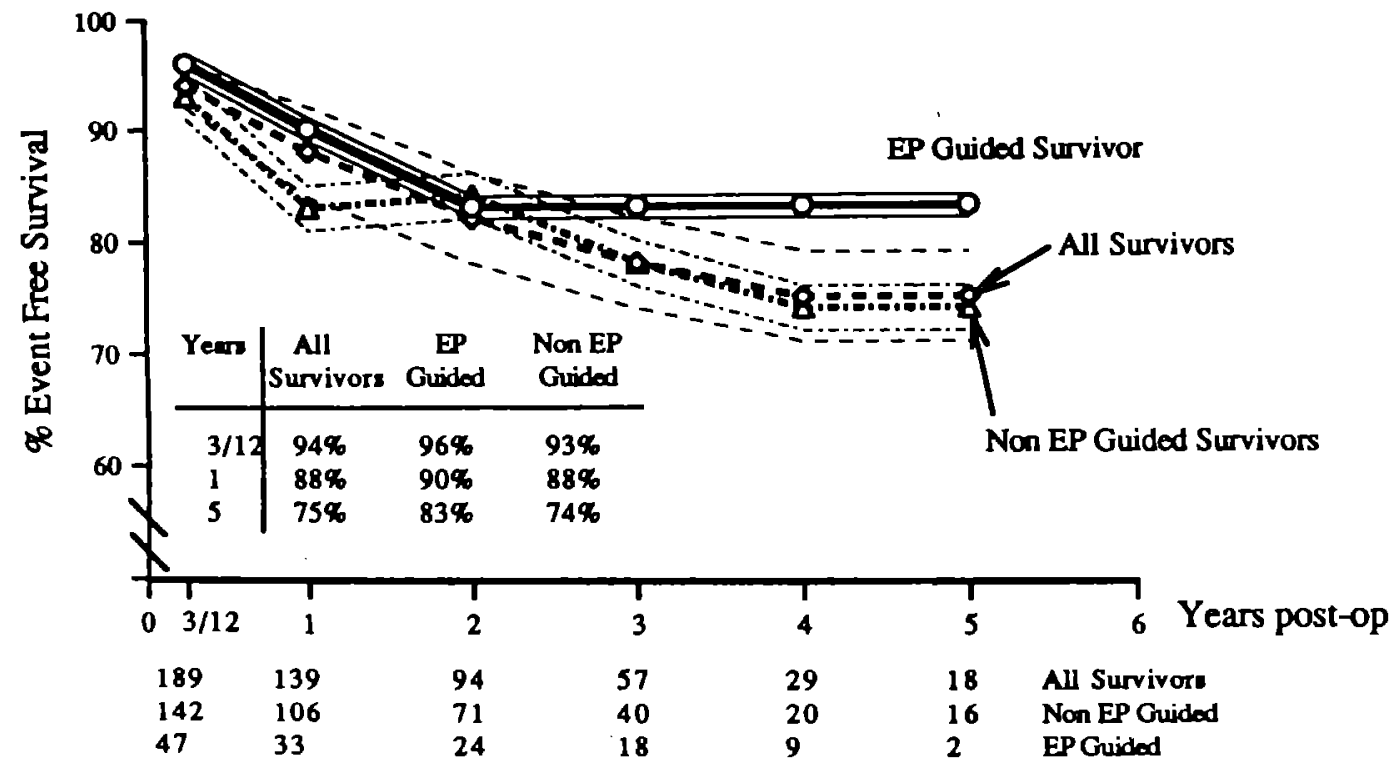

Fig. 6. Time-related freedom from ventricular arrhythmias, in all patients and stratified by use of electrophysiologically $(E P)$ guided therapy. The table provides survival at specified intervals. The numbers below the horizontal axis give the number of patients who were continuing to be followed up in each group. The dashed lines enclose the $70 \%$ confidence limits. Note that each event is represented twice, once in the All Survivors curve and again in either the EP Guided Survivors curve or Non-EP Guided Survivors curve. The vertical axis was broken to improve visualization of differences. 
Risk-adjusted analysis confirmed advanced age as a risk factor for death early after operation (see Table VI), but with a weak coefficient, age alone was a poor predictor of 5-year survival. Only when other risk factors were present did the predicted 5-year mortality for a 70 -year-old patient exceed $30 \%$. These observations suggest that in an otherwise healthy patient, CABG should not be denied solely on the basis of advanced age.

Survival in medically treated patients with severely impaired $\mathrm{LV}$ function and congestive symptoms has been reported to be as low as $18 \%$ at 5 years. ${ }^{5}$ Despite higher initial risk, CABG does improve symptoms and prolong survival when these patients have reversible ischemia and operable CAD. $4,6,7,14,22,27$ Thus, although we have identified $\mathrm{CHF}$ as a risk factor for death, CABG may substantially improve survival in many of these patients.

Patients with grossly dilated ischemic cardiomyopathy ( $\mathrm{LV}$ end-diastolic dimension $>70 \mathrm{~mm}$ ) are poor candidates for CABG and are perhaps better treated by cardiomyoplasty or cardiac transplantation. ${ }^{28,29}$ Dynamic cardiomyoplasty can improve $\mathrm{LV}$ function and CHF; however, because it requires more than 2 weeks of skeletal muscle preconditioning, it would be unsuitable in patients who require immediate therapy. 27,28

The risk factors reported in this study provide for patient-specific estimates of survival. When multiple risk factors are present in a patient with minimal extracardiac disease, transplantation would likely be a better option. For example, a woman with diffuse distal disease or CHF may have a predicted 5-year survival of less than $20 \%$. If this patient was an acceptable candidate, transplantation would be recommended.

Ventricular arrhythmias. Ventricular arrhythmias are a common cause of sudden death in the natural history of patients with reduced ventricular function. ${ }^{2,10,30-32}$ Even after successful revascularization, the risk of recurrence of arrhythmias is high, ${ }^{11,12}$ necessitating specific postoperative management.

Preoperative and postoperative electrophysiologic testing, to guide specific pharmacologic therapy, has been shown to reduce arrhythmic complications. $^{8,11-13,22}$ In patients who have a pharmacologically resistant condition, an implantable cardioverter-defibrillator is recommended. ${ }^{27,33-35}$ In this series, preoperative electrophysiologic testing was not performed; however, selected patients had postoperative testing (see Methods) and were treated with specific antiarrhythmic medication or an implantable cardioverter-defibrillator (see Table V). Ideally, all patients should have had preoperative electrophysiologically testing, directing placement of an implantable cardioverter-defibrillator or permanent implantable leads at the time of revascularization. $^{9}$

Our results indicate that patients who were identified at high risk for arrhythmic complications (those with sustained inducible ventricular arrhythmias) benefited from electrophysiologically guided management. None of the patients who receiving electrophysiologically guided management had a sudden cardiac death, and ventricular arrhythmias were less prevalent in this high-risk group than in the remaining patients $(17 \%$ vs. $26 \%, p=$ not significant). When arrhythmic complications did occur after electrophysiologically guided treatment, they were probably due to the development of drug resistance.

Some patients whose initial electrophysiologically studies were negative (without inducible sustained VT/VF) did have VT/VF during the follow-up period. Because arrhythmic complications rarely occur when results of a recent electrophysiologically examinative are negative, ${ }^{30-35}$ periodic postoperative testing might have helped a few patients, but the cost of such a strategy would be prohibitive. In the near future, smaller endocardial pacing and defibrillating systems, which can be placed percutaneously, may be an effective option for these patients. ${ }^{36}$

\section{Conclusion}

CABG in patients with severely impaired LV function appears beneficial if ischemia is reversible (salvageable myocardium) and the vessels are operable. Use of retrograde (coronary sinus) cardioplegia decreases early mortality. A management strategy that addressed congestive symptoms and ventricular arrhythmias resulted in acceptable survival. If characteristics associated with poor survival are identified, improved patient selection may be possible. An effective, timely revascularization with good myocardial protection improves survival in the early phase.

REFERENCES

1. Christakis GT, Weisel RD, Fremes SE, et al. Coronary artery bypass grafting in patients with poor ventricular function. $\mathbf{J}$ Thorac Cardiovasc Surg 1992;103:1083-92.

2. Zubiate P, Kay JH, Mendez AM. Myocardial revascularization for the patients with drastic impairment of function of the left ventricle. J Thorac Cardiovasc Surg 1977;73:84-6. 
3. Hochberg MS, Parsonnet V, Gielchinsky I, Hussain SM. Coronary artery bypass grafting in patients with ejection fraction below forty percent. J Thorac Cardiovasc Surg 1983;86:519-27.

4. Spencer FC, Green GE, Tice DA, Wallsh E, Mills NL, Glassman E. Coronary artery bypass grafts for congestive heart failure: a report of experience with 40 patients. J Thorac Cardiovasc Surg 1971;62:529-42.

5. Miller DC, Stinson EB, Alderman EL. Surgical treatment of ischemic cardiomyopathy: Is it ever too late? Am J Surg 1081;141:688-93.

6. Jones EL, Craver JM, Kaplan JA, et al. Criteria for operability and reduction of surgical mortality in patients with severe left vertricular ischemia and dysfunction. Ann Thorac Surg 1978;25:413-24.

7. Tyras DH, Kaiser GC, Barnes HB, Pennington DG, Codd JE, Willman, VL. Global left ventricular impairment and myocardial revascularization: determinants of survival. Ann Thorac Surg 1984;37:47-51.

8. Wilber DJ, Garan H, Finkelstein D, et al. Out of hospital arrest. N Engl J Med 1988;318:19-24.

9. Kron IL. When does one replace the heart in ischemic cardiomyopathy? Ann Thorac Surg 1993;55:581.

10. Holmes DR, Davis KB, Mock MB, et al. The effect of medical and surgical treatment on sudden cardiac death in patients with coronary artery disease: a report from the Coronary Artery Surgery Study. Circulation 1986;73:1254-63.

11. O'Rourke RA. Role of myocardial revascularization in sudden cardiac death. Circulation 1992;85(Suppl)I:112-7.

12. Kaiser GA, Thurer RJ. Surgical approaches to treatment of ventricular arrhythmias. J Am Coll Cardiol 1990;15:267-73.

13. Kelly P, Ruskin JN, Vlahakis GJ, Buckley MJ Jr, Freeman CS, Garan H. Surgical coronary revascularization in the survivors of prehospital cardiac arrest: its effects on inducible ventricular arrhythmias and long term survival. J Am Coll Cardiol 1990;15:267-73.

14. Sanchez JA, Smith CR, Drusin RE, Reison DS, Malm JR, Rose EA. High risk reparative surgery, a neglected alternative to heart transplantation. Circulation 1990;82(Suppl):IV302-5.

15. Luciani GB, Faggian TL, Razzolini R, Livi U, Bortolotti U, Mazzucco A. Severe ischemic left ventricular failure: coronary operation or heart transplantation. Ann Thorac Surg 1993;55:719-23.

16. Goldman L, Hashimoto B, Cook EF. Comparative reproducibility and validity of systems for assessing cardiovascular function: class advantages of new specific activity scale. Circulation 1981;64:1227-34.

17. Burch GE, Giles TD, Colcolough HL. Ischemic cardiomyopathy. Am Heart J 1970;79:291-2.

18. Kaplan EL, Meier P. Nonparametric estimation from incomplete observations. J Am Stat Assoc 1958;53:457-81.

19. Blackstone EH, Naftel DC, Turner ME JT. The decomposition of time varying hazard into phases, each incorporating a separate stream of concomitant information. J Am Stat Assoc 1986;81:615-24.

20. Bounous EP, Mark DB, Pollock BG, et al. Surgical survival benefits for coronary disease patients with left ventricular dysfunction. Circulation 1988;78(Pt 2):I151-7.

21. Johnson WD, Brenovitz JB, Kayser LL. Factors influencing long term (10-15 year) survival after a successful coronary artery bypass operation. Ann Thorac Surg 1989;48:19-25.

22. Kron IL, Lerman BB, Haines DE, Flanagan TL, DiMarco JP. Coronary artery bypass grafting in patients with ventricular fibrillation. Ann Thorac Surg 1989;48:85-9.

23. Lansman SL, Chen M, Galla, et al. Coronary bypass with ejection fraction of 0.20 or less using centigrade cardioplegia: long term follow up. Ann Thorac Surg 1993;56:480-6.

24. Milano CA, White WD, Smith R, et al. Coronary artery bypass in patients with severely depressed ventricular function. Ann Thorac Surg 1993;56:487-93.

25. Misare BD, Krukenkamp IB, Lazer ZP, Levitsky S. Retrograde is superior to antigrade continuous warm cardioplegia for acute cardiac ischemia. Circulation 1992;86(Suppl): II393-7.

26. Grundy SR, Wang NAN, Sciolaro CM, Shattuck H, Bailey LL. Coronary artery bypass in patients with ejection fraction less than $15 \%$, preliminary result using continuous warm blood retrograde cardioplegia. J Heart Failure 1993;Abstract Suppl I:398.

27. Magovern JA, Magovern GJ Sr, Maher TD Jr, et al. Operation for congestive heart failure: transplantation, coronary artery bypass, cardiomyoplasty. Ann Thorac Surg 1993;56: 418-25.

28. Moreira LP, Stolf NAG, Brocchi EA, et al. Latissimus dorsi cardiomyoplasty in the patients with dilated cardiomyopathy. Circulation 1990;82(Suppl):IV257-63.

29. Laks H, Aharon A, Drinkwater D, et al. Ischemic cardiomyopathy: results of heart transplantation and coronary revascularization. J Heart Failure 1993;Abstract Suppl I:751.

30. Jeevanandam V, Bielefeld MR, Auteri JS, et al. The implantable defibrillator: an electronic bridge to cardiac transplantation. Circulation 1992;86(Suppl):II276-9.

31. Lampert S, Lown B, Graboys TB, Podrid PJ, Blatt CM. Determinants of survival in patients with malignant ventricular arrhythmias associated with coronary artery disease. Am J Cardiol 1988:61:791-7.

32. Myerburg RJ, Kessler KM, Estes D, et al. Long term survival after prehopsital cardiac arrest: analysis of outcome during an eight year study. Circulation 1984;70:538-46.

33. Tam SKC, Miller JM, Edmunds LH Jr. Unexplained sustained ventricular tachyarrhythmias after cardiac operation. $\mathbf{J}$ Thorac Cardiovasc Surg 1991;102:883-9.

34. Freedman RA, Swerdlow CD, Suderholm-Difatte V, Mason JW. Prognostic significance of arrhythmia inducibility or non inducibility at the initial electrophysiological study in survivors of cardiac arrest. Am J Cardiol 1988;61:578-82.

35. Mirowski $M$. The automatic implantable cardioverter and defibrillator: an overview. J Am Coll Cardiol 1985;6:461-6.

36. Saksena S, Poezobutt-johanos M, Castle LW, et al. Long term multicenter experience with second generation implantable pacemaker-defibrillator in patients with malignant tachyarrhythmias. J Am Coll Cardiol 1992;19:490-9. 